\title{
Relative position of the central hole after EVO-ICL implantation for moderate to high myopia
}

\author{
Xiaojian $\mathrm{He}^{1 \dagger}$, Lingling $\mathrm{Niu}^{2,3,4 \dagger}$, Huamao Miao ${ }^{2,3,4}$, Feng Zhao ${ }^{2,3,4,5}$ and Xingtao Zhou ${ }^{2,3,4^{*}}$ (D)
}

\begin{abstract}
Background: This study aimed to evaluate the relative position of the central hole $\left(C_{H}\right)$ of EVO Implantable Collamer Lens (EVO-ICL), the pupil center $\left(C_{P}\right)$, and the corneal center $\left(C_{C}\right)$ after implantation of EVO-ICLs for moderate to high myopia.
\end{abstract}

Methods: Eighty-nine eyes of forty-seven patients with moderate to high myopia were evaluated. The mean preoperative spherical equivalent (SE) was $-12.58 \pm 4.13 \mathrm{D}$. A routine postoperative follow-up was performed within 1 $\sim 12$ months. Positions of the $C_{H}$ of EVO-ICLs, the $C_{P}$ and the $C_{C}$ were recorded using a slit lamp anterior segment photography system, and their relative distances were calculated with the Visio image analysis software.

Results: All surgeries were performed safely, and no complications were observed in follow-ups $4.3 \pm 4.82$ months after surgery. At the last follow-up, the safety index (postoperative CDVA/preoperative CDVA) was $1.23 \pm 0.48$, and the efficacy index (postoperative UDVA/preoperative CDVA) was $1.08 \pm 0.31$. The $C_{H}$ in 85 eyes (95.51\%) was superior to the $C_{C}$, with $47.19 \%$ (42/89) on the temporal side and $48.31 \%$ (43/89) on the nasal side. The $C_{H}$ in 84 eyes (94.38\%) was located on the temporal side of the $C_{p}$, with $56.18 \%$ (50/89) superior and $38.2 \%(34 / 89)$ inferior to the $C_{p}$. The $C_{p}$ of 85 eyes (95.51\%) was superior on the nasal side of the $C_{C}$. On the defined $x$-axis, the average distance from the $C_{H}$ to $C_{C}$ was significantly shorter than the average distance from the $C_{p}$ to $C_{C}(p<0.001)$.

Conclusions: An imperfect match between the central hole of EVO-ICLs and the pupil center does not necessarily indicate ICL dislocation. Compared to the pupil center, the position of the central hole of EVO-ICL is closer to the corneal center.

\section{Background}

Implantation of a posterior chamber phakic Implantable Collamer Lens (ICL ${ }^{\mathrm{Tm}}$, STAAR Surgical, Nidau, Switzerland) has proved to be safe and effective to correct moderate to high myopia $[1,2]$. There is no limit to the corneal thickness of the ICL implantation, which preserves the integrity of the cornea and the

\footnotetext{
*Correspondence: doctzhouxingtao@163.com

${ }^{+}$Xiaojian He and Lingling Niu contributed equally to this work.

2Eye Institute and Department of Ophthalmology, Eye \& ENT Hospital, Fudan University, Shanghai, China

${ }^{3} \mathrm{NHC}$ Key Laboratory of Myopia (Fudan University); Key Laboratory of Myopia, Chinese Academy of Medical Sciences, Shanghai, China Full list of author information is available at the end of the article
}

accommodation function of the lens after surgery. More importantly, the implantation of ICL is reversible.

In refractive surgery, accurate centration helps to maximize visual outcomes and is considered to be of great importance [3]. Ideally, the position of the corrected center should be aligned to the optical axis or to the intersection point between the optical axis and the anterior corneal surface [4]. However, it is not possible to directly observe the central position of ICL. EVO Implantable Collamer Lens (EVO-ICL) with CentraFLOW technology is characterized by a $360 \mu \mathrm{m}$ central hole that can allow natural circulation of the aqueous humour and can decrease the risk of cataract, high intraocular

C C The Author(s). 2020 Open Access This article is licensed under a Creative Commons Attribution 4.0 International License, which permits use, sharing, adaptation, distribution and reproduction in any medium or format, as long as you give appropriate credit to the original author(s) and the source, provide a link to the Creative Commons licence, and indicate if changes were made. The images or other third party material in this article are included in the article's Creative Commons licence, unless indicated otherwise in a credit line to the material. If material is not included in the article's Creative Commons licence and your intended use is not permitted by statutory regulation or exceeds the permitted use, you will need to obtain permission directly from the copyright holder. To view a copy of this licence, visit http://creativecommons.org/licenses/by/4.0/. The Creative Commons Public Domain Dedication waiver (http://creativecommons.org/publicdomain/zero/1.0/) applies to the data made available in this article, unless otherwise stated in a credit line to the data. 
pressure (IOP) and corneal endothelial cell loss after ICL implantation [5, 6]. Moreover, it provides an opportunity to directly observe the central position of the EVO-ICL in the posterior chamber. However, it is a common occurrence that the location of the central hole $\left(\mathrm{C}_{\mathrm{H}}\right)$ of the EVO-ICL is not perfectly aligned with the pupil center $\left(C_{P}\right)$. As the structure of the anterior segment of the eye has changed after the implantation of ICL, ultrasound biomicroscopy (UBM) [7], optical coherence tomography (OCT) [8], and rotating Scheimpflug imaging (Pentacam) [9] are used to evaluate the position and the vault of the implanted ICL, as well as relationships between the ICL and its adjacent structures. However, the position of the ICL relative to the corneal center $\left(C_{C}\right)$, which was defined as the intersection between the longest horizontal and vertical diameters of the corneal ellipse, has not yet been reported. Therefore, in this study, we aimed to measure the position of the central hole of the EVO-ICL relative to the corneal center and the pupil center, which may be of potential clinical benefit.

\section{Methods \\ Subjects}

This observational study was conducted on patients who underwent EVO-ICL implantation from January 2016 to October 2016 in the Department of Eye \& ENT Hospital of Fudan University. In accordance with the Declaration of Helsinki, all patients provided written informed consent after receiving detailed explanation of the risks and benefits of the study. The study was approved by the Ethics Committee of the Eye \& ENT Hospital (EENT) Fudan University.

The study was conducted on 89 eyes from 47 patients (19 males and 28 females, mean age $29.6 \pm 7.42$ years) who were recruited. The inclusion criteria for patients who underwent ICL implantation were as follows: age between 20 and 45 years, stable refractive error (refractive error change of $\leq 0.50 \mathrm{D}$ in the past 2 years), spherical refraction of over $-3.00 \mathrm{D}$, astigmatism of up to $-6.00 \mathrm{D}$, and no contact lens use for 2 weeks. Exclusion criteria were anterior chamber depth $(\mathrm{ACD})<2.80 \mathrm{~mm}$, endothelial cell density (ECD) $<2000$ cells $/ \mathrm{mm}^{2}$, a history of ocular surgery, any chronic systemic disease, inflammation or trauma, and a history of ocular conditions other than myopia with or without astigmatism (suspicion of cornea, cataract, keratectasia, glaucoma, macular degeneration, retinal detachment, or neuro-ophthalmic disease).

\section{EVO-ICL}

EVO-ICL corrects $-0.50 \mathrm{D}$ to $-18.00 \mathrm{D}$ myopic spherical refraction and up to $-6.00 \mathrm{D}$ cylindrical refraction. The size of the EVO ICL was individually selected based on the horizontal white-to-white (WTW) distance by IOLmaster and the ACD by Pentacam camera system
(Oculus, Germany) following the manufacturer's recommendations. We calculated the size on the website at http://ocos.staarag.ch. The software is version 4.08 for ICL V4c. Power calculation for the EVO-ICL was performed by the software provided by the manufacturer (STAAR Surgical) using a modified vertex formula.

\section{Surgical procedure and follow-ups}

Two experienced surgeons (XZ and XW) performed all implantations. Chen $\mathrm{X}$ et al. have previously described the surgical procedure [9]. Briefly, before surgery, the pupils were dilated. The anterior chamber was filled with sodium hyaluronate (ProVisc, Alcon), and an EVO-ICL was inserted through a $3.0 \mathrm{~mm}$ incision in the temporal corneal limbus using an injector cartridge (STAAR Surgical Co), then positioned in the posterior chamber. The remaining viscoelastic surgical agent was removed using balanced salt solution, before a miotic agent was instilled into the anterior chamber. Postoperative medications included $0.3 \%$ tobramycin, $0.1 \%$ fluorometholone, non-steroidal anti-inflammatory (NSAID) and artificial tears eye drops.

We determined manifest refraction (spherical equivalent, SE), uncorrected distance visual acuity (UDVA), corrected distance visual acuity (CDVA), IOP (Canon, Japan), endothelial cell density (ECD, by SP-2000P, Topcon Corporation, Japan), standard slit-lamp biomicroscopic and funduscopic examinations preoperatively and all follow-ups. Anterior chamber depth (ACD) was measured from the corneal endothelium to the anterior lens using a Pentacam camera system and horizontal corneal diameter (white-to-white, WTW) using IOLMaster before surgery. Central corneal thickness (Pentacam), axial length (IOLMaster Carl Zeiss, Germany) and ultrasound biomicroscopy (UBM; Quantel Medical, France) were performed preoperatively.

\section{Image analysis}

Under the same illumination conditions of $330 \mathrm{~lx}$, which was monitored using a photometer (Digitales Luxmeter, Sensorshop24@ ${ }^{@}$, Germany), all images were collected in the same room at a 10x magnification using a slit lamp anterior segment photographic system (YZ5FI Slit Lamp + SLICPS 2). Patients sat comfortably with their eyes facing straight ahead. The diffused light from the slit lamp was illuminated $60^{\circ}$ from the temporal side. Using Visio image analysis software (version 2013), the size of the center hole was fixed to $360 \mu \mathrm{m}$ (7.5 pixels) in both the horizontal (X-axis) and vertical (Y-axis) axis, and the image size was then adjusted accordingly. The average horizontal and vertical relative corneal diameters were $214.23 \pm 14.66$ pixels and $201.78 \pm 12.39$ pixels, respectively, and the average horizontal and vertical pupil diameters were $52.87 \pm 11.95$ pixels and $50.58 \pm 11.65$ pixels, respectively. Images confirmed that both the cornea and 
the pupil were elliptical (Fig. 1). The actual magnification of the image was calculated according to the following equation: WTW $(\mathrm{mm})$ /relative horizontal diameter of the cornea $(\mathrm{mm})$. Similar to the method reported by Hoang et al. [10], the central hole of EVO-ICL $\left(\mathrm{C}_{\mathrm{H}}\right)$, the corneal center $\left(\mathrm{C}_{\mathrm{C}}\right)$, and the pupil center $\left(\mathrm{C}_{\mathrm{P}}\right)$ were defined as the intersection between the longest horizontal and vertical diameters of the respective ellipse. Each measurement was performed three times by the same physician, and the results were averaged.

In this study, we set the $C_{C}$ of the fitted corneal image as the reference point $(0,0)$ and the position of $C_{H}$ and $C_{P}$ as $(X, Y)$ using the following formula: $D=\left(X^{2}+Y^{2}\right)^{1 / 2}$ and calculated the relative distances from the center hole to the corneal center, $\mathrm{D}(\mathrm{H}-\mathrm{C})$; the pupil center to the corneal center, $\mathrm{D}(\mathrm{P}-\mathrm{C})$; and the center hole to the pupil center $\mathrm{D}(\mathrm{H}-\mathrm{P})$ (Fig. 2). According to the equation: actual distance $\mathrm{D}=$ relative distance $\mathrm{D}$ * WTW $(\mathrm{mm}) /$ relative horizontal diameter of the cornea $(\mathrm{mm})$, the actual distances of $\mathrm{Ð}(\mathrm{H}-\mathrm{C}), \mathrm{P}(\mathrm{P}-\mathrm{C})$ and $Đ(\mathrm{H}-\mathrm{P})$ were calculated respectively. In all images, the $\mathrm{X}$-axis value of the left eye was converted to a negative value, which was converted to the same nasal and temporal direction as the right eye. The $\mathrm{X}$-axis ( $\mathrm{DHx}$ and $\mathrm{ÐPx}$ ) and the $\mathrm{Y}$-axis (ĐHy and $Đ \mathrm{Py}$ ) on $Ð(\mathrm{H}-\mathrm{C})$ and $\mathrm{Ð}(\mathrm{P}-\mathrm{C})$ are shown in Fig. 2. The $\mathrm{X}$-axis (ĐHPx) and the $\mathrm{Y}$-axis (ĐHPy) on $\mathrm{D}(\mathrm{H}-\mathrm{P})$ were defined as the $\mathrm{X}$-axis and the $\mathrm{Y}$-axis of the vector of $Đ(H-P)$.

\section{Kappa angle}

Pupil offset was used as the estimate of the Kappa angle and defined as the vector between the corneal vertex and the pupil center in the corneal plane. Pupil offset was measured using Pentacam. The $\mathrm{x}$-offset $(\mathrm{K}-\mathrm{x})$ and $\mathrm{y}$ -

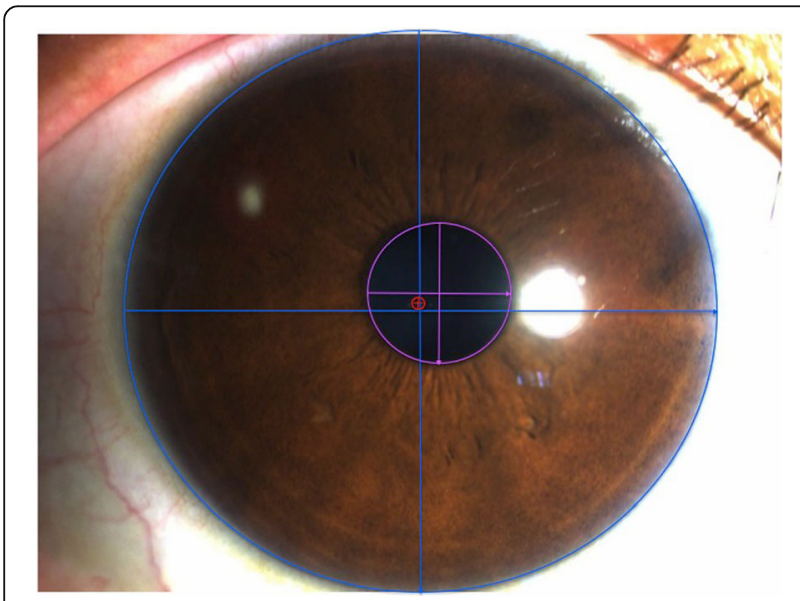

Fig. 1 The red line and circle is shown for the central hole of the EVO-ICL, the purple line and circle is shown for the pupil center, and the blue line and circle is the corneal center of the right eye. Visio image analysis software was used for image analysis

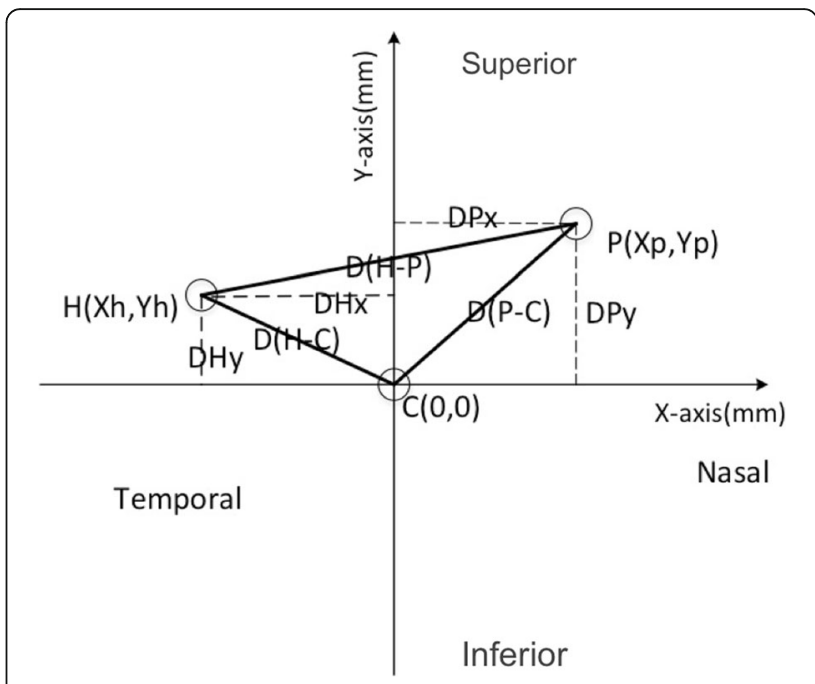

Fig. 2 Relative position of the central hole of EVO-ICL, the corneal center and the pupil center

offset (K-y) of the vector were recorded respectively. A positive value is defined as the pupil center nasal to the pachy apex ( $\mathrm{x}$-offset) and as the pupil center upper to the pachy apex (y-offset).

\section{Statistical analysis}

All statistical analyses were performed using Stata statistical software, version 14.1 (Stata Corporation, College Station, TX, USA). The Wilcoxon Signed-rank test was used for statistical analysis to compare $Đ(\mathrm{H}-\mathrm{C})$ and $(\mathrm{P}$ $\mathrm{C})$, ĐHx and ĐPx, ĐHy, and ĐPy. Spearman's correlation analysis was used to assess the correlation between $Ð(\mathrm{H}-\mathrm{C})$ and $Đ(\mathrm{P}-\mathrm{C})$, ĐHx and $Đ P x$, and $Đ H y$ and $Đ P y$, $\mathrm{K}-\mathrm{x}(\mathrm{K}-\mathrm{y})$ and $Đ H x$ (ĐHy), K-x (K-y) and ĐHPx (ĐHPy). Results are expressed as mean \pm standard deviation (SD), and statistical significance was set at $p<0.05$.

\section{Results}

Safety and efficacy

All surgical procedures were completed successfully, and no complications occurred throughout the entire followup period. The median follow-up period was $4.3 \pm 4.82$ months (range: $1 \sim 12$ months). No postoperative complications were observed, and no loss of corrected distance visual acuity (CDVA) was recorded throughout the entire follow-up period. The mean preoperative spherical equivalent (SE) was $-12.58 \pm 4.13 \mathrm{D}$ (range: -5.75 to 22.75D). The safety index (postoperative CDVA/preoperative CDVA) was $1.23 \pm 0.48$. No patient had CDVA loss at any follow-up. The efficacy index (postoperative UDVA /preoperative CDVA) was $1.08 \pm 0.31$, and the mean vault was $525.93 \pm 228.43 \mu \mathrm{m}$ (range: $100 \sim$ $1070 \mu \mathrm{m})$. No eye of ECD decreased to $<2000$ cells $/ \mathrm{mm}^{2}$ throughout the entire follow-up period. 
Relative position of $C_{H}$ to the $C_{C}$ and the $C_{P}$

Relative to the $\mathrm{C}_{\mathrm{C}}$ the $\mathrm{C}_{\mathrm{H}}$ of EVO-ICL was superior to the $\mathrm{C}_{\mathrm{C}}$ in $85 / 89$ eyes (95.51\%), with $42 / 89$ (47.19\%) superior on the temporal side, $43 / 89$ (48.31\%) superior on the nasal side, $3 / 89$ (3.37\%) inferior on the temporal side, and 1/89 (1.12\%) inferior on the nasal side (Fig. 3a). Relative to the $\mathrm{C}_{\mathrm{P}}$, the $\mathrm{C}_{\mathrm{H}}$ was located on the temporal side in $84 / 89$ eyes ( $94.38 \%$ ), with $50 / 89$ (56.18\%) superior on the temporal side, 34/89 (38.2\%) inferior on the temporal side, $2 / 89(2.25 \%)$ superior on the nasal side, and 3/89 (3.37\%) inferior on the nasal side (Fig. 3b).

\section{Relative position of the $C_{P}$ to the $C_{C}$}

$C_{P}$ was superior on the nasal side of the $C_{C}$ in $85 / 89$ eyes $(95.51 \%)$, with $3 / 89(3.37 \%)$ superior on the temporal side, and $1 / 89(1.12 \%)$ inferior on the nasal side in (Fig. 4).

\section{Distance between the $C_{H}$, the $C_{C}$ and the $C_{P}$}

The average $Đ(\mathrm{H}-\mathrm{C})$ and $Đ(\mathrm{P}-\mathrm{C})$ were $0.37 \pm 0.18 \mathrm{~mm}$ and $0.42 \pm 0.18 \mathrm{~mm}$ respectively, and were approaching a statistically significant difference $(p=0.058)$. The average
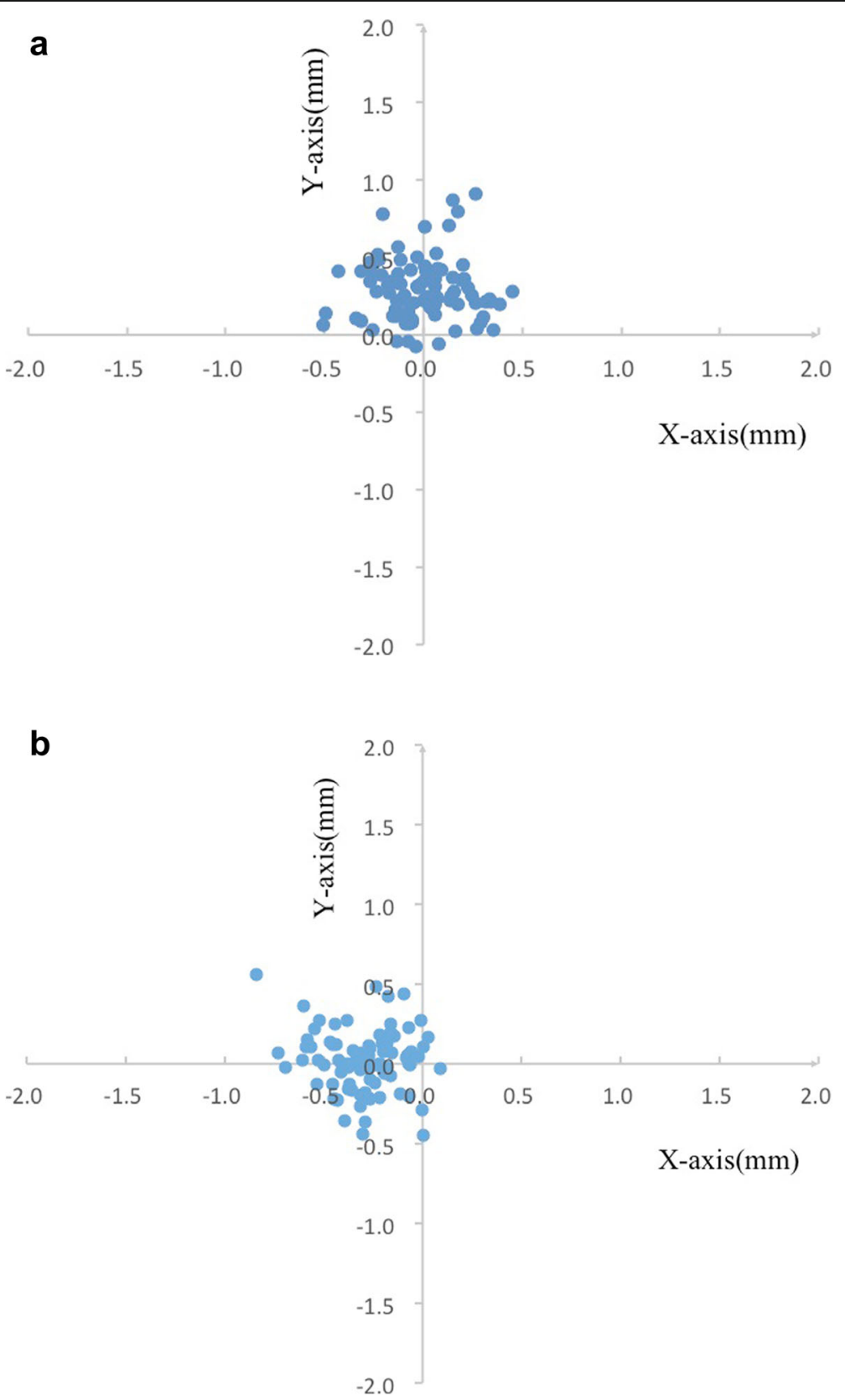

Fig. 3 a Scatter plot of the central hole relative to the corneal center. $(0,0)$ represents the corneal center. $\mathbf{b}$ Scatter plot of the central hole relative to the pupil center. $(0,0)$ represents the pupil center 


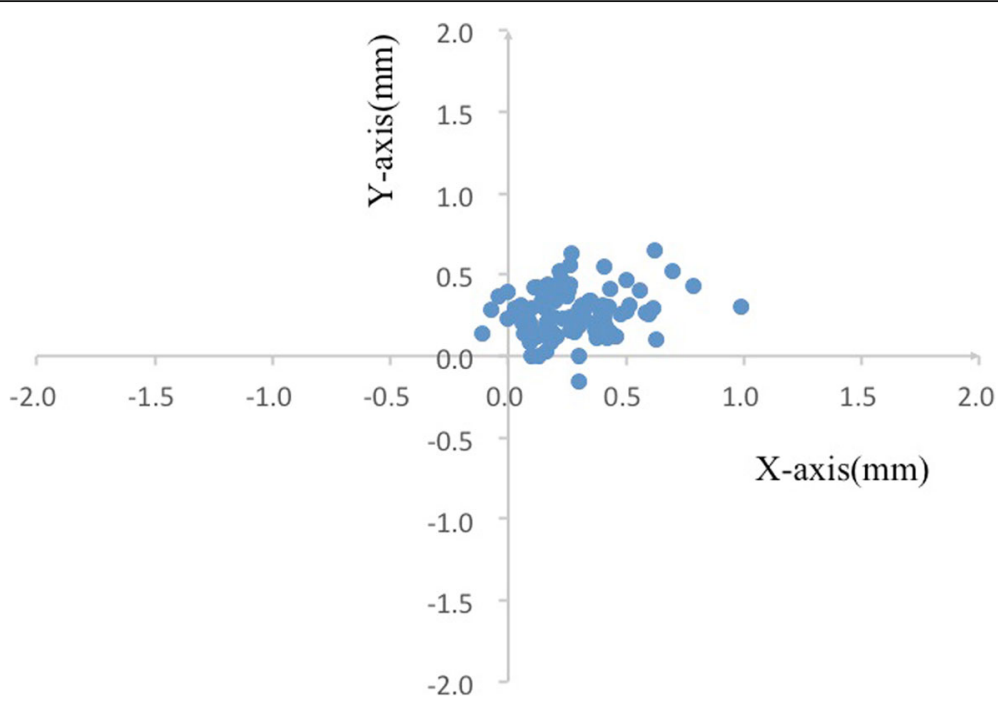

Fig. 4 Scatter plot of the pupil center relative to the corneal center. $(0,0)$ represents the corneal center

ĐHx and ĐPx were $0.16 \pm 0.12 \mathrm{~mm}$ and $0.28 \pm 0.19 \mathrm{~mm}$ respectively, and were statistically different $(p<0.001)$. The average ĐHy and ĐPy were $0.30 \pm 0.19 \mathrm{~mm}$ and $0.27 \pm 0.14 \mathrm{~mm}$ respectively, and the difference was not statistically significant $(p=0.624)$. The average $\mathrm{Ð}(\mathrm{H}-\mathrm{P})$ was $0.35 \pm 0.18 \mathrm{~mm}$ (range: $0.05 \sim 1.01 \mathrm{~mm}$ ). Though there was no significant correlation between $Đ(\mathrm{H}-\mathrm{C})$ and $Đ(\mathrm{P}-\mathrm{C})(r=0.20, p=0.062)$, ĐHx was positively correlated with ĐPx $(r=0.57, p<0.001)$ and ĐHy with ĐPy $(r=0.42, p<0.001)$.

\section{Relationships of kappa angle with $Ð(\mathrm{H}-\mathrm{C})$ and $Ð(\mathrm{H}-\mathrm{P})$}

There was no significant correlation between $\mathrm{K}-\mathrm{x}$ and ĐHx $(r=-0.011, P=0.923)$, or between K-y and ĐHy $(r=-0.155, P=0.162)$, while the relationships between $\mathrm{K}-\mathrm{x}$ and ĐHPx $(r=-0.253, P=0.021), \mathrm{K}-\mathrm{y}$ and ĐHPy $(r=-0.435, \quad P<0.001) \quad$ was significantly correlated postoperatively.

\section{Discussion}

The new EVO-ICL has reduced risk of high intraocular pressure (IOP), cataracts, and endothelial cell loss after ICL implantation and is more effective and safer than conventional ICLs due to natural flow through a central whole $[5,6,11]$. The position of the ICLis critical during follow-up since it may be of consequence to corrected visual acuity as well as postoperative complications such as cataracts and glaucoma $[5,11]$. However, the position of conventional ICLs, such as the V4, is difficult to evaluate without the use of UBM or a Pentacam $[12,13]$. In this study, we were able to evaluate the relative position of the EVO-ICL in the posterior chamber directly based on the position of the center hole in a slit lamp image, without the need for additional inspection.
The selection of ICL diameter depends mainly on the preoperative horizontal corneal diameter (WTW) and anterior chamber depth [14]. There are many studies available on the correlation between WTW and STS. Seo et al. [15] reported that the WTW diameter matched with the distance of the STS on the horizontal direction as measured by UBM. However, Biermann [16] compared emmetropic and myopic eyes, and found that the horizontal direction of the emmetropic STS had a significant correlation with WTW, but there was only a weak correlation between the two in the myopic population. Though the STS distance may not completely be estimated by WTW, the vertical ciliary sulcus was longer than the horizontal ciliary sulcus, which meant the ciliary sulcus was vertical ellipse had been identified. ICLs are usually positioned horizontally in the ciliary sulcus with a rotation of $<5^{\circ}$ even implantations of toric intraocular collamer lenses (TICLs) $[17,18]$. The haptics of ICL are located at the ciliary sulcus, Hence, the horizontal position of the central hole may be closer to the horizontal center of the ellipse ciliary sulcus. Here, we described the relative position of the central hole, the corneal center and the pupil center, and found that most of central holes of EVO-ICLs were superior to the corneal center and were on the temporal side of the pupil center. Although the difference between $\mathrm{Ð}(\mathrm{H}-\mathrm{C})$ and $\mathrm{P}(\mathrm{P}-\mathrm{C})$ did not reach statistical significance difference $(p=0.058), \mathrm{Ð}(\mathrm{H}-\mathrm{C})$ was significantly shorter than $\mathrm{Ð}(\mathrm{P}-$ $C)$ on the $\mathrm{X}$-axis $(p<0.001)$, indicating that the center of the ICL should be positioned relative to the corneal center, which is consistent with our observation. Therefore, it is reasonable to evaluate the position of the EVO-ICL according to the relative position of the central hole to the corneal center. 
The mean distance between the pupil center and the corneal center in our study was $0.42 \pm 0.18 \mathrm{~mm}$, which was longer than the $0.27 \pm 0.14$ reported by Medby et al. [19]. This discrepancy could possibly have resulted from the different imaging methods or due the different research conditions. It has been reported that the location of the pupil center may change under various illumination conditions [20-22]. Yang et al. [20] reported that the pupil center moved temporally towards the corneal center under mesopic or pharmacologically dilated conditions. And Fay [23] reported that, as the pupil constricts, the most common shift of the pupil center was in a superonasal direction. We also found that the central hole and the pupil center were both upwards relative to the corneal center. Other studies using UBM have shown that ICLs were in contact with the posterior surface of iris [7, 24], suggesting that the mechanical friction between the iris and the ICL could be responsible for the concordant movement of the implanted ICLfollowing the shift of the pupil. Spearman's correlation analysis showed that $Đ H x$ was positively correlated with ĐPx $(r=0.57, p<0.001)$, and ĐHy was positively correlated with ĐPy $(r=0.42, p<0.001)$, suggesting that shifts of both the central hole of the EVO-ICL and the pupil center relative to the corneal center were concordant in the horizontal and vertical directions. However, there was no direct correlation between $\mathrm{Ð}(\mathrm{H}-\mathrm{C})$ and $\mathrm{Ð}(\mathrm{P}-\mathrm{C})$ $(r=0.20, p=0.062)$.

Consideration of the kappa angle is important for correct centration of refractive treatments [25], therefore the influence of kappa angle on the position of ICL was analyzed. We can find that the distance between $\mathrm{K}-\mathrm{x}$ and ĐHPx or K-y and ĐHPy was significantly corrected, while not K-x and ĐPx or K-y and ĐPy. This may indicate that due to the influence of the Kappa angle, if the pupil center is used as the reference, the position of the central hole would affected by the position and diameter of the pupil. In that case the results may be different under different lighting environments. However if the corneal center is used as the reference, the results may be relatively stable. In this study, we used the slit lamp anterior segment photographic system and objective image analysis to evaluate the relationship between the central hole and the corneal center. This has the benefits of being easy to use, non-invasive, and not requiring any additional equipment, which means that it has certain feasible advantages over other methods for clinical observation.

The current study has several limits. Firstly, this was a cross-sectional study with inconsistent follow-up time from 1 month to 12 months after surgery, and it lacked a comparison of the position changes over time, especially in the early period after surgery. As the vault decreased most significantly at first months after surgery [26], it would have been useful to determine if the center of EVO changed from the first day to the first-month visit, which may influence the position of ICL. Secondly, we did not analyze the relationships between the distance of the central hole to the corneal center and clinical outcomes, such as visual quality, after ICL implantation which may need to be further investigated in future studies.

\section{Conclusions}

Although the central hole of the EVO-ICL does not perfectly match the pupil center, it is not necessarily indicative of an ICL dislocation. Compared to the pupil center, the position of the central hole of the EVO-ICL is closer to the corneal center.

\section{Abbreviations}

EVO-ICL: Evolution Visian Implantable Collamer Lens; SE: Spherical equivalent; D: Diopter; $C_{H}$ : Central hole of EVO-ICL; $C_{C}$ : Corneal center; $C_{p}$ : Pupil center; IOP: Intraocular pressure; UBM: Ultrasound Biomicroscopy; OCT: Optical coherence tomography; ACD: Anterior chamber depth; ECD: Endothelial cell density; WTW: White-to-white; NSAID: Non-steroidal anti-inflammatory drugs; UDVA: Uncorrected distance visual acuity; CDVA: Corrected distance visual acuity; SD: Standard deviation; STS: Sulcus to sulcus

\section{Acknowledgements}

The authors thank Lin Wang and Tian Han of the Eye Department of EENT Hospital for their helpful advice. We would also like to thank all the patients participating in the study.

\section{Authors' contributions}

Literature screening and selection was performed by $X H$ and LN. XZ participated in the design of the study. LN drafted the manuscript. $\mathrm{XH}$ carried out the statistical analysis. HM and FZ prepare and review of the manuscript. XZ has given final approval of the version to be published. All authors read and approved the final manuscript.

\section{Funding}

This work was supported by National Natural Science Foundation of China (Grant No. 81770955 and 81570879), Project of Shanghai Science and Technology (Grant No .17140902900 and 17411950200), Joint research project of new frontier technology in municipal hospitals (SHDC12018103) and National Natural Science Foundation of China for Young Scholars (Grant No. 81600762). The funding agencies had no role in study design, data collection and analysis, interpretation of data, or writing the manuscript.

\section{Availability of data and materials}

Data and materials are available upon request from the corresponding author at doctzhouxingtao@163.com.

\section{Ethics approval and consent to participate}

This study was conducted in accordance with the principles of the Declaration of Helsinki and was approved by the Ethics Committee of the Eye and ENT Hospital Review Board of Fudan University. Written informed consent was obtained from all patients after the nature and possible consequences of the study were explained.

\section{Consent for publication}

All participants in this study signed written consent forms for the publication of their relevant clinical data.

\section{Competing interests}

The authors declare that there is no competing interest.

\section{Author details}

${ }^{1}$ Department of Ophthalmology, Hangzhou First People's Hospital, Zhejiang University School of Medicine, Hangzhou, China. ${ }^{2}$ Eye Institute and 
Department of Ophthalmology, Eye \& ENT Hospital, Fudan University, Shanghai, China. ${ }^{3} \mathrm{NHC}$ Key Laboratory of Myopia (Fudan University); Key Laboratory of Myopia, Chinese Academy of Medical Sciences, Shanghai, China. ${ }^{4}$ Shanghai Research Center of Ophthalmology and Optometry, Shanghai, China. ${ }^{5}$ Shuguang Hospital affiliated to Shanghai University of Traditional Chinese Medicine, Shanghai, China.

Received: 4 July 2019 Accepted: 14 July 2020

Published online: 28 July 2020

\section{References}

1. Sanders DR, Doney K, Poco M, Group ICLiToMS. United States Food and Drug Administration clinical trial of the implantable Collamer Lens (ICL) for moderate to high myopia: three-year follow-up. Ophthalmology. 2004; 111(9):1683-92.

2. Igarashi A, Shimizu K, Kamiya K. Eight-year follow-up of posterior chamber phakic intraocular lens implantation for moderate to high myopia. Am J Ophthalmol. 2014;157(3):532-9 e531.

3. Vinciguerra P, Randazzo A, Albe E, Epstein D. Tangential topography corneal map to diagnose laser treatment decentration. J Refract Surg (Thorofare, NJ : 1995). 2007;23(9 Suppl):S1057-64.

4. Chang DH, Waring GO. The subject-fixated coaxially sighted corneal light reflex: a clinical marker for centration of refractive treatments and devices. Am J Ophthalmol. 2014;158(5):863-74

5. Alfonso JF, Lisa C, Fernandez-Vega L, Almanzar D, Perez-Vives C, MontesMico R. Prevalence of cataract after collagen copolymer phakic intraocular lens implantation for myopia, hyperopia, and astigmatism. J Cataract Refract Surg. 2015;41(4):800-5.

6. Goukon H, Kamiya K, Shimizu K, Igarashi A. Comparison of corneal endothelial cell density and morphology after posterior chamber phakic intraocular lens implantation with and without a central hole. $\mathrm{Br} J$ Ophthalmol. 2017;101(11):1461-5.

7. Garcia-Feijoo J, Alfaro IJ, Cuina-Sardina R, Mendez-Hernandez C, Del Castillo JM, Garcia-Sanchez J. Ultrasound biomicroscopy examination of posterior chamber phakic intraocular lens position. Ophthalmology. 2003;110(1):163-72.

8. Baikoff G, Lutun E, Wei J, Ferraz C. Contact between 3 phakic intraocular lens models and the crystalline lens: an anterior chamber optical coherence tomography study. J Cataract Refract Surg. 2004;30(9):2007-12.

9. Chen X, Miao H, Naidu RK, Wang X, Zhou X. Comparison of early changes in and factors affecting vault following posterior chamber phakic implantable Collamer Lens implantation without and with a central hole (ICL V4 and ICL V4c). BMC Ophthalmol. 2016;16(1):161.

10. Hoang TA, Macdonnell JE, Mangan MC, Monsour CS, Polwattage BL, Wilson SF, Suheimat M, Atchison DA. Time course of pupil center location after ocular drug application. Optom Vis Sci. 2016;93(6):594-9.

11. Higueras-Esteban A, Ortiz-Gomariz A, Gutierrez-Ortega R, Villa-Collar C, Abad-Montes JP, Fernandes P, Gonzalez-Meijome JM. Intraocular pressure after implantation of the Visian implantable Collamer Lens with CentraFLOW without iridotomy. Am J Ophthalmol. 2013;156(4):800-5.

12. Yan Z, Miao H, Zhao F, Wang X, Chen X, Li M, Zhou X. Two-year outcomes of Visian implantable Collamer Lens with a central hole for correcting high myopia. J Ophthalmol. 2018;2018:8678352.

13. Zhao J, Luo D, Sun Y, Niu L, Zhao F, Wang X, Wang H, Chen Q, Zhou X. Implanting a posterior chamber phakic intraocular lens in highly myopic eyes with peripheral primary iris and ciliary body cysts. Eur J Ophthalmol. 2019;29(2):171-7.

14. Choi KH, Chung SE, Chung TY, Chung ES. Ultrasound biomicroscopy for determining visian implantable contact lens length in phakic $1 \mathrm{OL}$ implantation. J Refract Surg. 2007:23(4):362-7.

15. Seo JH, Kim MK, Wee WR, Lee JH. Effects of white-to-white diameter and anterior chamber depth on implantable collamer lens vault and visual outcome. J Refract Surg. 2009;25(8):730-8.

16. Biermann J, Bredow L, Boehringer D, Reinhard T. Evaluation of ciliary sulcus diameter using ultrasound biomicroscopy in emmetropic eyes and myopic eyes. J Cataract Refract Surg. 2011;37(9):1686-93.

17. Mori T, Yokoyama S, Kojima T, Isogai N, Ito M, Horai R, Nakamura T, Ichikawa K. Factors affecting rotation of a posterior chamber collagen copolymer toric phakic intraocular lens. J Cataract Refract Surg. 2012;38(4):568-73.

18. Park SC, Kwun YK, Chung ES, Ahn K, Chung TY. Postoperative astigmatism and axis stability after implantation of the STAAR Toric implantable Collamer Lens. J Refract Surg. 2009;25(5):403-9.
19. Mabed IS, Saad A, Guilbert E, Gatinel D. Measurement of pupil center shift in refractive surgery candidates with caucasian eyes using infrared pupillometry. J Refract Surg. 2014;30(10):694-700.

20. Yang $Y$, Thompson K, Burns SA. Pupil location under mesopic, photopic, and pharmacologically dilated conditions. Invest Ophthalmol Vis Sci. 2002; 43(7):2508-12.

21. Camellin M, Gambino F, Casaro S. Measurement of the spatial shift of the pupil center. J Cataract Refract Surg. 2005;31(9):1719-21.

22. Erdem U, Muftuoglu O, Gundogan FC, Sobaci G, Bayer A. Pupil center shift relative to the coaxially sighted corneal light reflex under natural and pharmacologically dilated conditions. J Refract Surg. 2008;24(5):530-8.

23. Fay AM, Trokel SL, Myers JA. Pupil diameter and the principal ray. J Cataract Refract Surg. 1992;18(4):348-51.

24. Jimenez-Alfaro I, Benitez del Castillo JM, Garcia-Feijoo J, Gil de Bernabe JG, Serrano de La Iglesia JM. Safety of posterior chamber phakic intraocular lenses for the correction of high myopia: anterior segment changes after posterior chamber phakic intraocular lens implantation. Ophthalmology. 2001;108(1):90-9.

25. Park CY, Oh SY, Chuck RS. Measurement of angle kappa and centration in refractive surgery. Curr Opin Ophthalmol. 2012;23(4):269-75.

26. Kojima T, Maeda M, Yoshida Y, Ito M, Nakamura T, Hara S, Ichikawa K. Posterior chamber phakic implantable collamer lens: changes in vault during 1 year. J Refract Surg. 2010;26(5):327-32.

\section{Publisher's Note}

Springer Nature remains neutral with regard to jurisdictional claims in published maps and institutional affiliations.
Ready to submit your research? Choose BMC and benefit from:

- fast, convenient online submission

- thorough peer review by experienced researchers in your field

- rapid publication on acceptance

- support for research data, including large and complex data types

- gold Open Access which fosters wider collaboration and increased citations

- maximum visibility for your research: over $100 \mathrm{M}$ website views per year

At $\mathrm{BMC}$, research is always in progress.

Learn more biomedcentral.com/submissions 